\title{
Control Theory Concepts Applied to Retail Supply Chain: A System Dynamics Modeling Environment Study
}

\author{
Balaji Janamanchi' ${ }^{1}$ and James R. Burns ${ }^{2}$ \\ ${ }^{1}$ Division of International Business and Technology Studies, Texas A\&M International University, 5201 University Blvd, \\ Laredo, TX 78041-1900, USA \\ ${ }^{2}$ Rawls College of Business Administration, Texas Tech University, ISQS Area, P.O. Box 42101, Lubbock, TX 79409-2101, USA \\ Correspondence should be addressed to Balaji Janamanchi; bjanamanchi@tamiu.edu
}

Received 21 May 2013; Accepted 5 September 2013

Academic Editor: Jing-song Hong

Copyright (C) 2013 B. Janamanchi and J. R. Burns. This is an open access article distributed under the Creative Commons Attribution License, which permits unrestricted use, distribution, and reproduction in any medium, provided the original work is properly cited.

Control theory concepts have been long used to successfully manage and optimize complex systems. Using system dynamics (SD) modeling methodology, which is continuous deterministic simulation modeling methodology, we apply control theory concepts to develop a suitable performance functional (or objective function) that optimizes the performance of a retail supply chain. The focus is to develop insights for inventory management to prevent stock-outs and unfilled orders and to fill customer orders at the lowest possible cost to supply chain partners under different scenarios, in a two-player supplier-retailer supply chain. Moderate levels of inventory, defining appropriate performance functional, appear to be crucial in choosing the right policies for managing retail supply chain systems. The study also demonstrated how multiple objectives can be combined in a single performance functional (or objective function) by carefully assigning suitable weights to the components of objectives based on their priority and the existence of possible trade off opportunities.

\section{Introduction}

There is no denying that supply chains are complex business systems and the more we know about them the better we can manage them. In this paper we focus on retailer supply chains, rather than manufacturer supply chains. Additionally, we demonstrate the use of control theory concepts to optimize the performance of the retail supply chain for predefined performance functional. One significant difference between manufacturers and retailers is that retailers do not have a manufacturing delay. However, both manufacturer and retailer have one week lead time delay. When the retailer transmits an order, one week is required to fill and ship the order; likewise when a manufacturer transmits a shop order to produce a product, one week is required to manufacture the product. Once the product is shipped, it is in-house at a retailer's facility and is available for sale. Structurally, this is significant. The structural model used for retailers does not include the manufacturing delay found in manufacturing models, typically known as cycle time. Further, the goals and objectives of retailers are different from those of manufacturers. Manufacturing supply chains are focused on minimizing a bullwhip effect, while retailers are more interested in minimizing unfilled order costs and inventorycarrying costs. This is the fabric, the substance, this paper will address - the supply-chain needs of retailers accomplished via a control theory optimization process.

This study is part of a series of studies aimed at gaining a deeper and better understanding of supply chain dynamics using system dynamics modeling methodology developed and enhanced over the past fifty years $[1,2]$. In prior studies effects of reduction in information delays and flow delays, as well as forecasting/smoothing, upon manufacturing supply chains have been explored $[3,4]$. The focus of our current study is to develop useful insights for inventory management to prevent stock-outs and unfilled orders under different scenarios, exclusively for retailers in a two-player supplierretailer supply chain. After all, the success of the supply chain lies in meeting customer orders in a timely manner at 
the lowest possible cost to the supply chain partners. Accordingly, the performance functional of unfilled orders at the retailer that addresses this supply chain metric begs attention and understanding.

The remainder of this paper is organized as follows. Section 2 reviews the relevant literature, discusses the modeling tool, and explains the general outline of a hypothetical supplier-retailer supply chain setup. The results from the simulation of the base case and several sets of alternative scenarios are presented in Section 3, followed by a discussion of insights that may be gained from these results. Finally, Section 4 lists the contributions/limitations of the current study and directions for future research.

\section{Materials and Method}

2.1. Literature Review. Lee et al. [5, 6] were among the first to identify and define the bullwhip effect in supply chains. Swaminathan et al. [7] employed a multiagent approach to the modeling of supply chains. Simulation provides an effective pragmatic approach to detailed analysis and evaluation of supply chain design and management alternatives. However, the utility of this methodology is hampered by the time and effort required to develop models with sufficient fidelity to the actual supply chain of interest. Swaminathan et al. describe a supply chain modeling framework designed to overcome this difficulty [7].

Chen et al. [8] quantify the bullwhip effect for a simple two-stage supply chain. Their model includes two factors that are commonly believed to cause the bullwhip effect: demand forecasting and order lead times. They extend their results to a multiple-stage supply chain and show that bullwhip effects can be reduced but not eliminated by centralizing demand data.

Huang et al. [9] performed a comprehensive review of the impacts of sharing production information on supply chain dynamics. The review proposes a loose reference framework to reflect major elements commonly involved in this type of research, including the decision level investigated, supply chain structure, research questions addressed, factors involved, supply chain dynamics measured, modeling methodology adopted, data analysis technique used, and findings and insights from the managerial perspective obtained. Fleisch and Tellkamp [10] discuss inventory accuracy and supply chain performance through the use of a chain of costs and out-of-stock levels.

Concurrently, retail supply chains have begun to engage the attention of researchers. Agrawal et al. [11] describe a mathematical modeling methodology for managing capacity, inventory, and shipments for an assortment of retail products produced by multiple vendors. The vendors differ in lead times, costs, and production flexibility. Product demand is uncertain and fluctuates over time. They develop an optimization model to choose the production commitments that will maximize the retailer's expected gross profit, given demand forecasts and vendors capacity and flexibility constraints. The model has been incorporated into a decision support system and developed in collaboration with supply chain planners at a global retailer of seasonal and fashion merchandise, which was a rather specialized focus.

Sparling proposed the use of simulation modeling technique to teach supply chain management concepts in undergraduate, graduate, and executive development programs [12]. Specifically, Sparling presented modified versions of Beer Game originally developed by the professors at the Sloan School of Management at MIT in the early 1960s, in support of his recommendations. He developed and presented introductory and advanced versions of modified Beer Game simulations.

Kent and Mentzer [13] investigate the effect of investment in interorganizational information technology in a retail supply chain. Holweg et al. [14] suggest that collaborative planning, forecasting and replenishment (and other similar collaborative strategies), has not brought the benefits in supply chains that were hoped for. They believe the reason is because of a lack of understanding regarding what these strategies can do. They use case studies to demonstrate what is necessary to make these collaborative strategies work.

Barratt and Oke [15] discovered that visibility has become a popular buzzword in the supply chain literature, but it remains an ill-defined and poorly understood concept. It is assumed that if companies across supply chains have visibility of demand, inventory levels, processes, and so forth, organizational performance improves. Their research explores the antecedents of high levels of supply chain visibility from a resource-based theory perspective across five different external supply chain linkages. They find that the level of visibility across these linkages differs considerably based on various contributing factors which are both technology and nontechnology based. Using resource-based theory, they identify those factors that can give a sustainable competitive advantage to a supply chain linkage through a "distinctive" or high level of visibility.

More recently, Jaber et al. [16] demonstrated that the entire supply chain benefits from implementing learningbased continuous quality improvements. The continuous improvement process is characterized by reduced set-up times, increased production capacity, and elimination of rework as a result of a learning-based improvement. They accomplish this by utilizing a hypothetical three-level supply chain (supplier-manufacturer-retailer) with a set of initial parametric settings and costs. They used EXCEL Solver enhanced by Visual Basic code, on several sets of examples with coordination and without coordination, and other variations of relevant parametric values.

Ding et al. [17] reiterated that information sharing plays a key role in generating higher profits for supply chains. They developed a mathematical model to deal with the issue of sharing profits arising out of information sharing amongst the supply chain partners of a three-echelon supply chain. They model a supply chain consisting of a "one manufacturer, $j$ homogeneous distributors, and $i$ homogeneous retailers" dealing in a single product over multiple periods.

Burns and Malone [18] have successfully demonstrated the use of control theory optimization techniques to system dynamics models by following the methodology introduced by Burns [19] in a path breaking work. More recently, Burns 
and Janamanchi [20] applied the control theory optimization technique in a contemporary simulation modeling language Vensim [21].

However, not much research appears to have been done to study the use of optimization process combined with dynamic simulation to address supply-chain policy issues related to the bottom line in retailing and to understand supply chain structural dynamics involved. This observation provides us with the motivation to undertake this study to understand these aspects of retail supply chains utilizing system dynamics modeling, the same methodology employed in the popular Beer Game simulation developed by professors at the Sloan School of Management at MIT in the early 1960s.

2.2. Model Description: Model Structure. The models utilized in this research are primarily simulation models of the continuous-dynamic type. The methodology utilized is known as system dynamics and was developed by Forrester [1, 22] and advanced by Sterman [2]. The software implementation tool utilized is Vensim [21]. The founder of system dynamics, Dr. Jay W. Forrester, was the first to use system dynamics to study the firm and its interaction with suppliers [3, 4]. More recently, system dynamicists have been studying supply chains, in general, using system dynamics methodology [2, 23-25].

2.3. Brief Overview of the Supply Chain Setup. Customers place orders for products with the retailer who places orders with his "upstream partner" who is a manufacturer (hereinafter referred to as supplier) for the required products. Both the retailer and supplier carry Finished Goods Inventories and have in place inventory policies. However, the supplier who is also the manufacturer, carries "work-in-process" (WIP) inventories denoting the presence of manufacturing cycle times. A cycle time of 4 weeks is considered in the model which is the typical cycle time for many products like, leather goods, mobile phones, LCDs, LEDs, and DVDs, and so forth. Similarly, the supplier and retailer have order forecasting policies in place using "exponential smoothing" methods with a smoothing alpha of 0.25 denoting a conservative approach.

System dynamics structure for the retailers consists of stock of Finished Goods and the customer order forecasting setup. The retailer has no work-in-process because no manufacturing is done at the retailer's location. This is the biggest difference between the stock-and-flow structure of the retailer and the stock-and-flow structure of the supplier/manufacturer (depicted in Figure 1). The basic constructs for the model structure are derived from state of the art models presented in Sterman [2]. Supplier structure includes the work in process and input coming from the upstream supplier. Supplier also has a workforce setup which includes hiring rate, quit rate, production normal, and overtime production, when required.

2.4. Overview of Retailer's Setup. Figure 1 depicts the retailer's Order filling process complete with customer order receipt, exponential forecasting, inward material receipt, and Finished Goods Inventory management. A week is the unit of time in this model. Customer orders initiate the action. This is the single most important exogenous input that we use to exercise and test the model. It will ultimately determine the quantity sold. Next is an exponential smoothing structure that partially determines the "desired order rate" based on a SMOOTHING FACTOR ALPHA. The desired order rate drives the supplier-manufacturer model in Figure 2 (in lower right-hand side of Figure 2). In all these figures, parameters (constants) are shown in all caps. The desired order rate for retailer is the sum of the "Forecast Order rate" and the "production adj for FG inventory."

2.5. Supplier/Manufacturer's Setup. Figure 2 depicts the supplier/manufacture's structure.

All quantities in Figure 2 end with "S1" to denote "supplier 1" and to distinguish them from similarly named quantities in retailer's part of the model. The information infrastructure starts with the "Forecast Order rateS1" stock on the lower right. The "desired Finished Goods coverageS1" is equal to the SAFETY STOCK LEVELS1 (one week). The "Forecast Order rateS1" per week is multiplied by the "desired Finished Goods coverage" to yield the "desired FG InventoryS1." The "production adj for FG InventoryS1" (production adjustment for Finished Goods Inventory) is then computed so as to correct the gap in "desired FG InventoryS1" versus actual "Finished Goods InventoryS1" divided by the FG INVENTORY ADJUSTMENT TIMES1; thus

$$
\begin{aligned}
& \text { "Production adj for FG InventoryS1" } \\
& =\text { (“desired FG InventoryS1" } \\
& \quad \text { - "Finished Goods InventoryS1") } \\
& \quad \times(\text { FG INVENTORY ADJUSTMENT TIMES1 })^{-1} .
\end{aligned}
$$

The "production adj for FG InventoryS1" is concerned with the rate at which FG safety stocks are replenished. Then, the "production adj for FG InventoryS1" is combined (literally added) with the "forecast order rate" to produce the "desired production rateS1" in Figure 1.

The "desired production rateS1" is multiplied by the PRODUCTION CYCLE TIMES1 to yield the "desired WIPS1". This is just a direct implementation of Little's Law [26]. Similar to the adjustment for Finished Goods, an "adjustment for WIPS1" is computed based on the following formula:

$$
\begin{aligned}
& \text { "Adjustment for WIPS1" } \\
& =\frac{(\text { Desired WIPS1 - Work in ProcessS1) }}{\text { WIP ADJUSTMENT TIMES1 }} .
\end{aligned}
$$




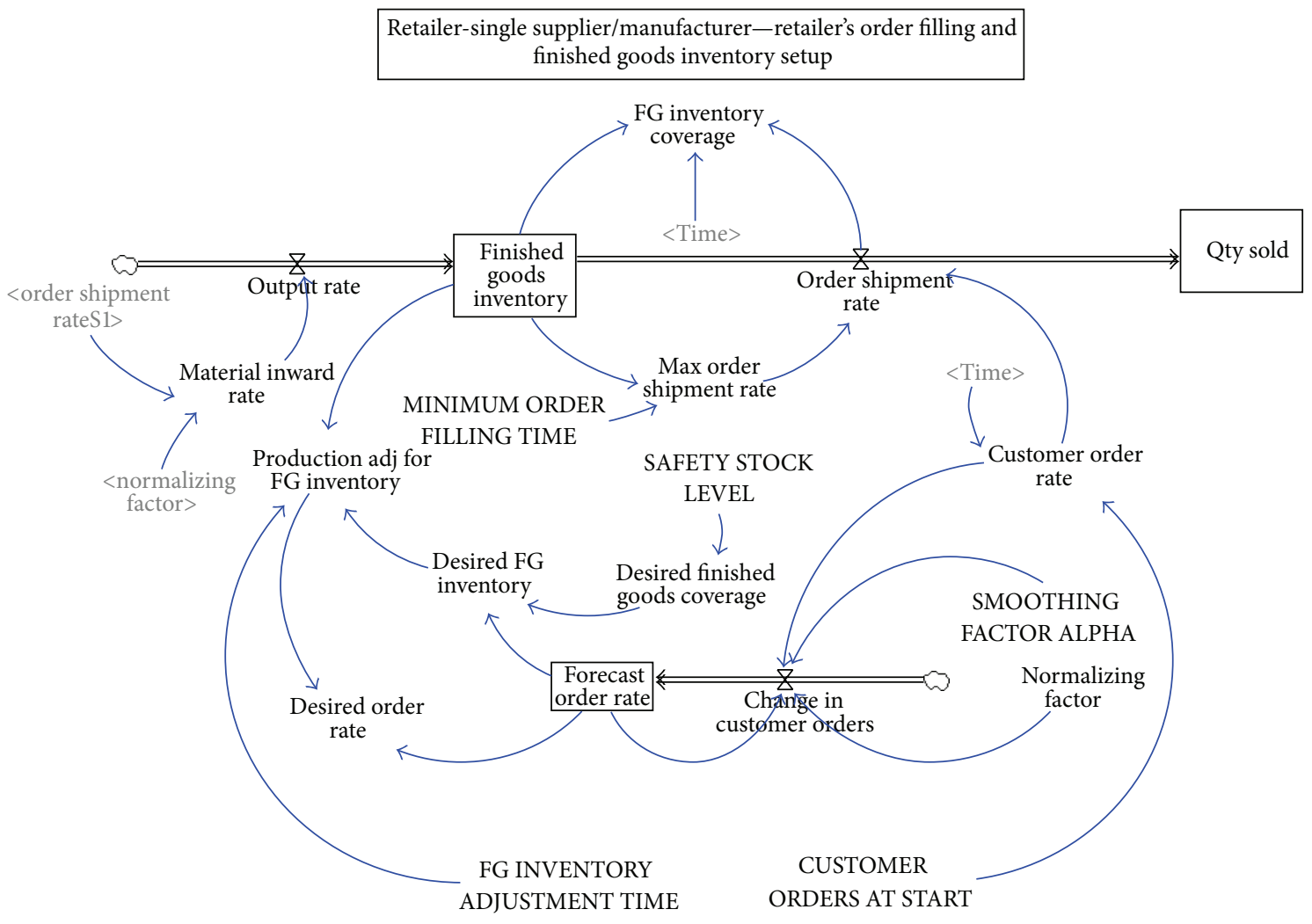

FIGURE 1: Retailers order-filling process and inventory management.

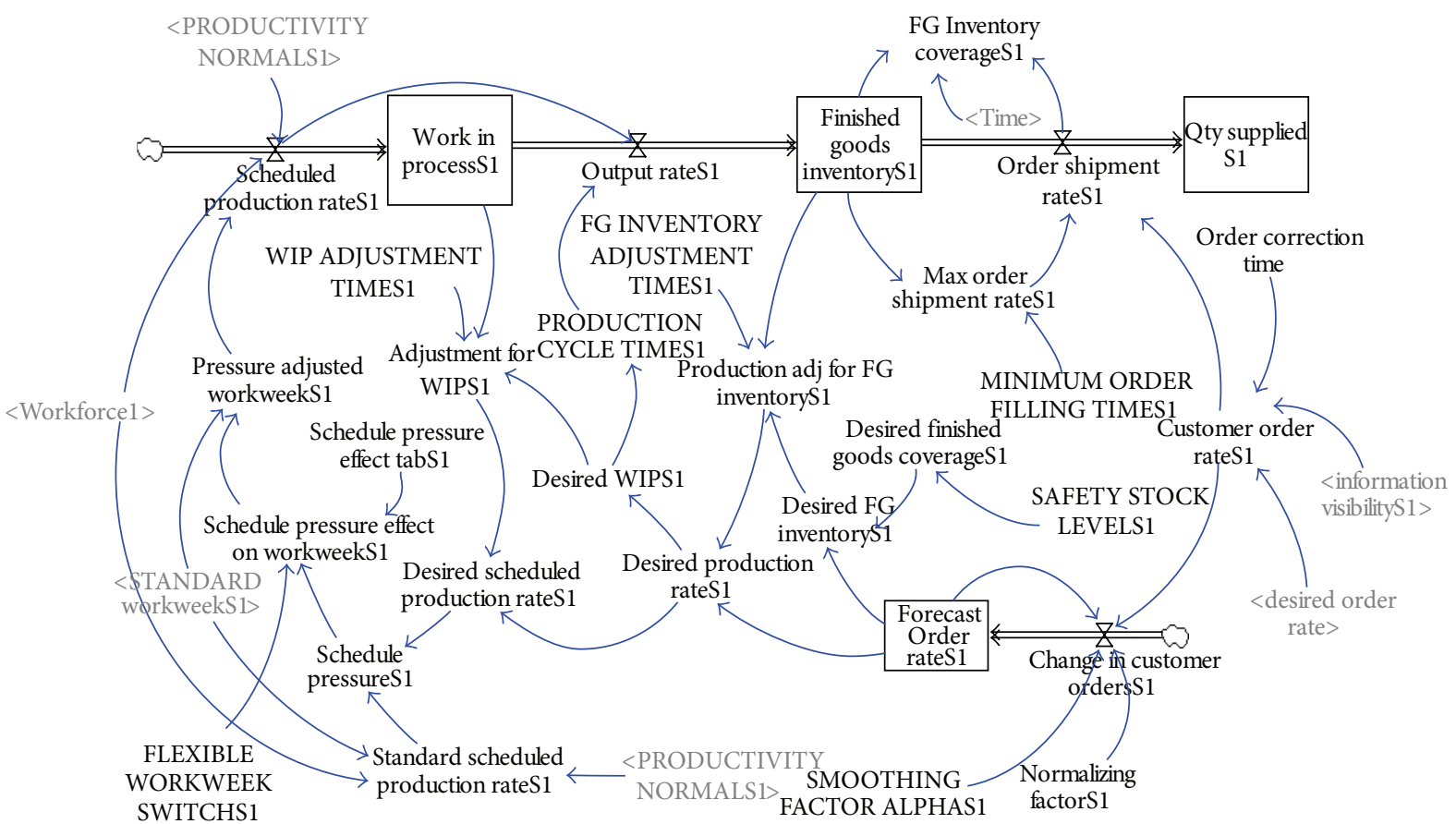

FIGURE 2: Supplier/manufacturer's setup—production and inventory view. 


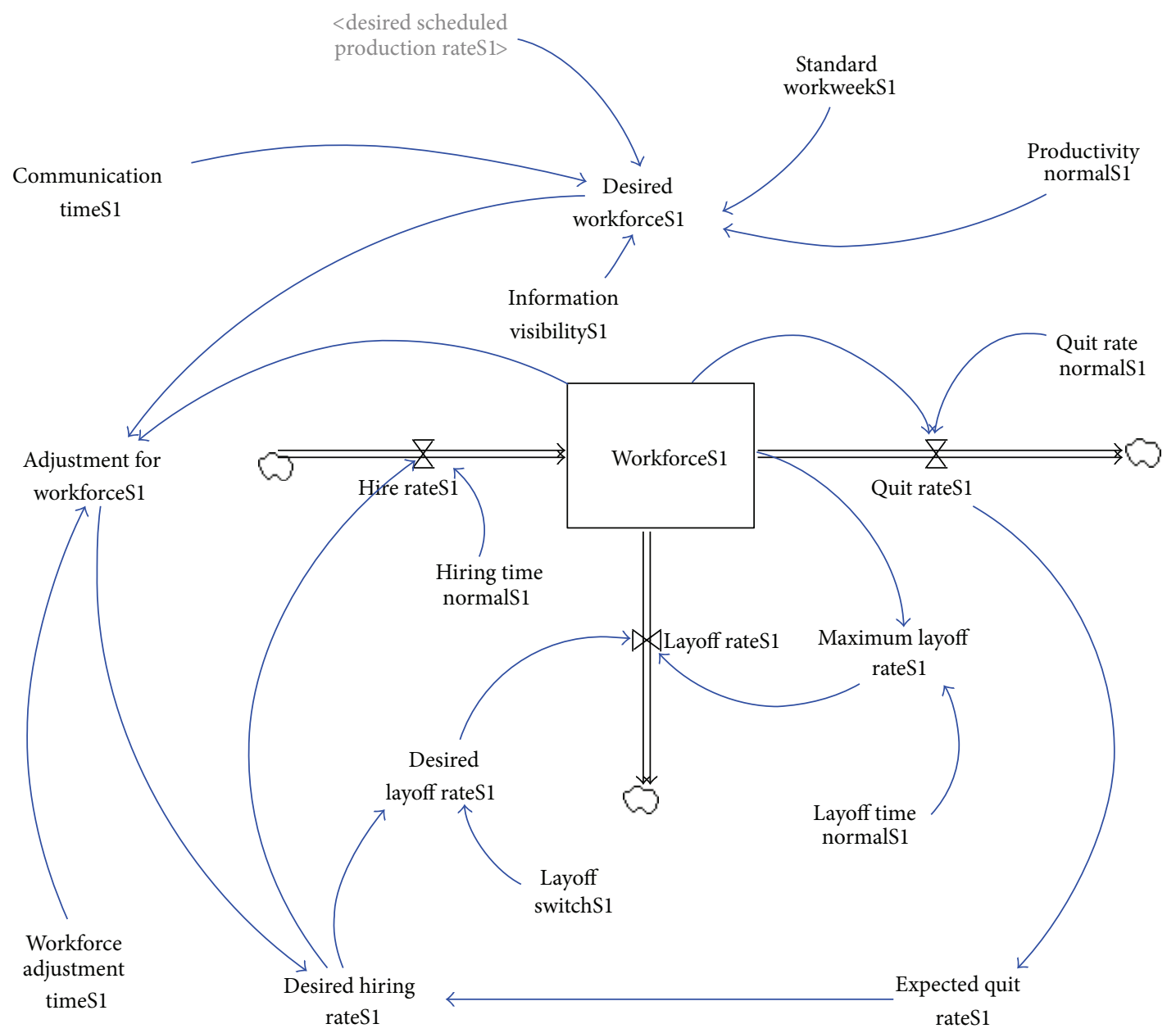

FIGURE 3: Workforce view of the supplier manufacturer.

The sum of the "desired production rateS1" and the "adjustment for WIPS1" yields the "desired scheduled production rateS1", that is,

"Desired scheduled production rateS1"

= "desired production rateS1" + "adjustment for WIPS1".

However, the manufacturer's desired production plans are limited by two main factors, availability of material inputs in the required numbers and availability of the required "workforceS1". Based on the available "workforceS1", "standard workweekS1", and PRODUCTIVITY NORMALS1, the "standard scheduled production rateS1" is determined as the product of these. PRODUCTIVITY NORMALS1 is assumed at 0.5 unit per/person $*$ hour, denoting half a unit of output per worker per hour. From the "desired scheduled production rateS1" and "standard scheduled production rateS1", the "schedule pressureS1" is computed as the ratio of these. Specifically, "schedule pressureS1" = "desired scheduled production rateS1"/“standard scheduled production rateS1". If the "schedule pressureS1" is greater than " 1 ", it indicates a shortage of "workforceS1"; on the other hand, if the "schedule pressure" is less than "1," it indicates an excess of "workforceS1". Typically, such excess or shortage of "workforceS1", as indicated by the "schedule pressureS1", will trigger action for adjustment in the workforce levelS1, either by way of decreases in the hiring or by way of increases in the hiring of additional workforce.

2.6. Workforce Sector Setup for Manufacturer. Figure 3 depicts the workforce portion of the model structure. Desired scheduled production rateS1, STANDARD WORKWEEKS1, and PRODUCTIVITY NORMALS1, along with communication timeS1 and information visibilityS1, combine to yield the "desired workforceS1" to support the production operations. Typically, in the absence of information visibility between functional areas, there is a one time-period (one week) delay of communicating the "desired scheduled production rate" to the personnel department. When information visibility (IV) is turned on, some information delays in the retailer and supplier components (Figures 1 and 2) are removed (assuming that the retailer/supplier has, in place, a suitable information system). One of those is the time required to perceive the need for changes in the workforce. Based on management's policy of 
adjusting the gaps in workforce, desired versus actual, an "adjustment for workforce" is computed. "WorkforceS1" is regularly depleted by the "quit rate" of the workforce. The "expected quit rate" for the next period is equal to the current period's "quit rate". The "desired hiring rate" is the sum of the "expected quit rate" and the "adjustment for workforce", to maintain an equilibrium level of "workforce". However, only positive values of "desired hiring rate" result in recruitment of "workforce". If "desired hiring rateS1" is negative, then such rate is used in computing the "desired lay off rate" depending upon management's policy on layoffs (LAYOFF SWITCHS1 value $1=$ yes and $0=$ no), "workforce" is laid off or is not laid off. For simplicity, we assume that the management does not practice layoffs in this study.

2.7. Initial Parameter/Policy Setting for Retailer and Supplier Manufacturer. Table 1 given lists the initial values for the major stocks and policy parameters of the retailer and the supplier in the model. Running time for the simulation is 100 weeks.

Table 2 gives details of various order scenarios simulated. Under the base case scenario, there is no change in the steady rate of customer orders, no randomness. Under the other six scenarios, the customer orders vary as stated in the above description of scenarios. The objective in choosing these variations in customer orders is to develop insights into the resultant response behavior of the system variables under alternate scenarios. As we know, random normal and random uniform distributions represent a stationary mean situation. Spiked orders and dipped orders represent periodic spike or dip in positive or negative direction. Upward trend and downward trend represent an upward trend in mean and downward trend in mean of the orders. These variations, because of certain commonalities among them, allow us to develop useful insights and inferences for policy formulation.

\section{Results and Discussion}

As discussed, we start the model simulation with the basecase, where the system is in steady state and the customer orders are received steadily at 1,000 units/week. We refer to this as one week of inventory. Inventory policies (one week safety stock) and forecast policies (exponential smoothing with alpha $=0.25$ ) are working perfectly for the retailer as well as his supplier. Then we continue with the scenarios listed in Table 1 and referred to in Section 2.7. Immediately, we observe (Figures 4 and 5) accumulation of unfilled orders at retailer as well as supplier. Retailer experiences unfilled orders so also the supplier (who is manufacturing the product) of moderate level under spiked orders scenario, a moderate level unfilled order under the six order situations listed in Table 2 and referred to in Section 2.7 combined with flexible work week policies. Highest level of unfilled orders is observed under random uniform order scenario. Figures 4 and 5 capture the unfilled orders at retailer and his supplier.

As we know, increasing safety stocks is the easiest way to avoid or eliminate unfilled orders; we first start with increasing the safety stocks both at retailer and supplier. When safety stocks are increased from 1 week $(1,000)$ to 1.5 weeks (1,500 units) at both the retailer's as well as supplier's facilities, the unfilled orders are reduced literally down to zero. As expected, Finished Goods hover around the 1.5 weeks level (1,500 units). But the question now is, is it possible to reduce the stock levels without compromising on elimination of stock outs? To answer this question, we attempt an optimization of the parametric settings with the objective of minimizing the unfilled orders at the retailer.

\subsection{Performance Functional for Optimization}

Optimization 1. First, for our purposes, borrowing an idea from control theory concepts $[18,19,27]$, we shall represent the dynamical model as a collection of explicit, nonlinear differential equations, with initial conditions $x_{0}$ for each state (stock), as follows:

$$
\dot{x}=f(x, u, t), \quad x\left(t_{0}\right)=x_{0} .
$$

Here " $x$ " is a vector of states (stocks), " $u$ " is a vector of control inputs, and " $t$ " is the independent variable time. The control input " $u$ " is selected from a space $M$ of possible control inputs. $M$ places a restriction on the control inputs, preventing unrealistic or impossible values from being chosen by the optimization algorithm. The control inputs are parameters and therefore not functions of time.

The value system model (which we shall refer to interchangeably as the index of performance or simply "objective") is defined as follows:

$$
I^{*}\left(u^{*}\right)=\lim _{u \in M} \int_{t_{0}}^{t_{f}} \phi(\mathrm{UOR}, \mathrm{UOS}, u, t) d t .
$$

Subject to

$$
\begin{aligned}
\dot{x} & =f(x, u, t), \quad x\left(t_{0}\right)=x_{0}, \\
M & =\left\{u \mid u_{i} \geq 0, \quad i=1, m\right\} .
\end{aligned}
$$

We start optimization of parametric settings with the objective of minimizing the unfilled orders at the retailer only (Optimization 1). So our index of performance at this stage may be defined as

$$
\operatorname{Min} I=\int_{t_{0}}^{t_{f}} C_{1} \cdot(\mathrm{UOR}) d t+\int_{t_{0}}^{t_{f}} C_{2} \cdot\|u-1\|_{w}^{2} d t .
$$

The first term seeks to minimize the unfilled orders at the retailer. UOR denotes the unfilled orders at the retailer. The second term minimizes the control effort required to accomplish the first one. The second term is optional in a Vensim environment, as the user is able to specify the start point of search as well as the permissible range of values for the parameters for the optimal parametric setting. Powell's "Hill Climbing" algorithm that is built into Vensim is used to perform the parametric optimization. We have the option of either dropping the second term from our index of performance or setting the corresponding coefficient value 
TABLE 1: Initial parameter settings.

\begin{tabular}{|c|c|c|c|}
\hline Parameter & Unit & Retailer & Supplier \\
\hline Simulation time & Weeks & 100 & 100 \\
\hline Customer orders at start & Units/week & 1000 & N/A \\
\hline Orders from retailer & Units/week & N/A & 1000 \\
\hline Smoothing factor alpha & Dimensionless & 0.25 & 0.25 \\
\hline Minimum order filling time & Weeks & 1 & 1 \\
\hline Safety stock level & Weeks & 1 & 1 \\
\hline FG inventory adjustment time & Weeks & 1 & 4 \\
\hline Production cycle time & Weeks & & 4 \\
\hline WIP adjustment time & Weeks & & 4 \\
\hline Standard workweek & Hours & 40 & 40 \\
\hline FWW: flexible work week—max (schedule pressure effect tabS1) & Hours & 50 & 50 \\
\hline FWW: flexible work week_-min (schedule pressure effect tabS1) & Hours & 30 & 30 \\
\hline Productivity normalS1 & Units/(hour*person) & & 0.5 \\
\hline WIP & Units & & 4000 \\
\hline Finished goods inventory, initial & Units & 1000 & 1000 \\
\hline \multicolumn{4}{|l|}{ Workforce view } \\
\hline Workforce adjustment timeS1 & Weeks & & 5 \\
\hline Communication timeS1 & Weeks & 1 & 1 \\
\hline Hiring time normalS1 & Weeks & N/A & 1 \\
\hline Quit rate normalS1 & $\mathrm{dmnl} /$ week & $\mathrm{N} / \mathrm{A}$ & 0.01 \\
\hline WorkforceS1 & Person & Not relevant & 50 \\
\hline
\end{tabular}
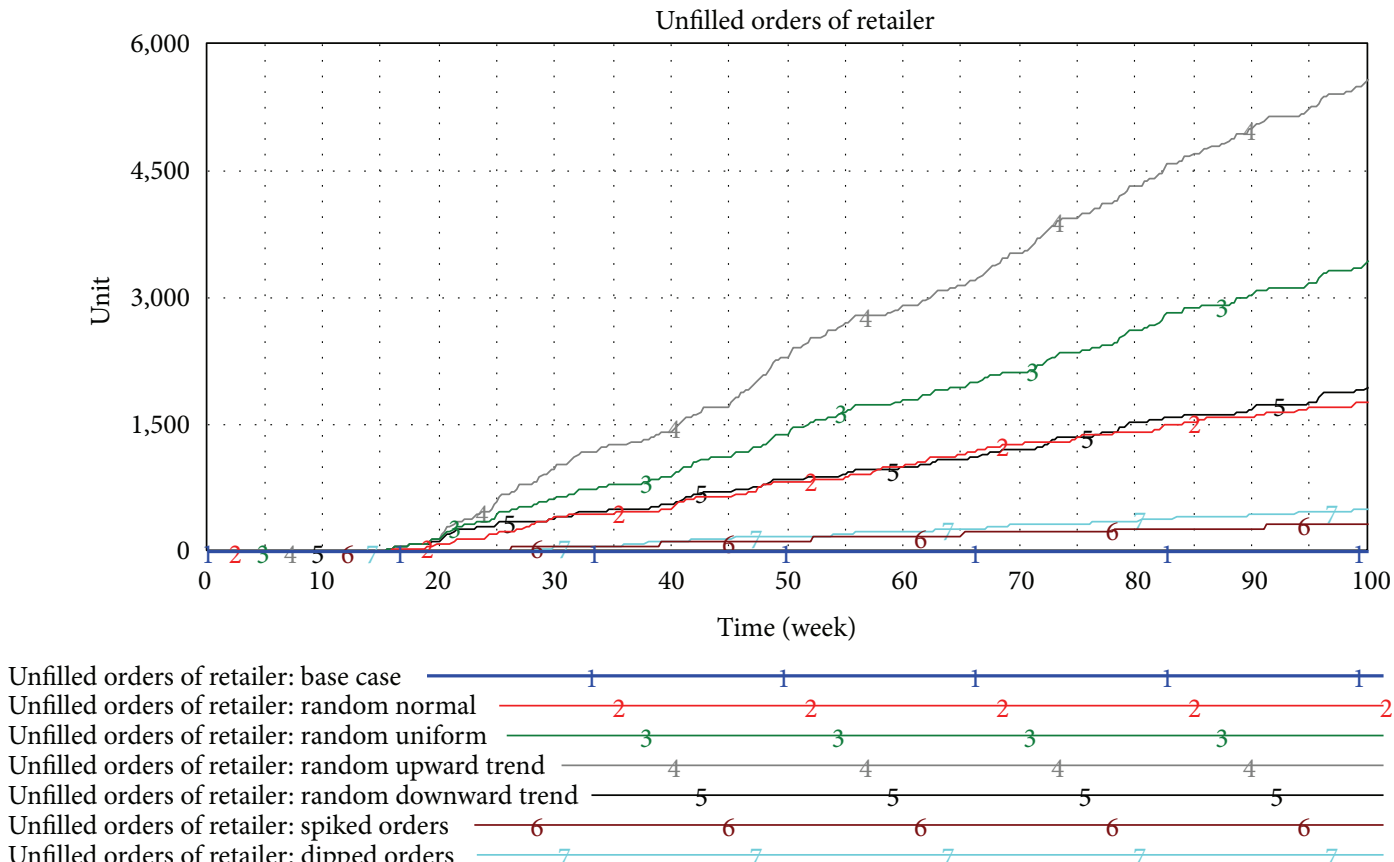

Unfilled orders of retailer: dipped orders

FIGURE 4: Unfilled Orders at retailer despite information visibility.

equal to 0 (zero). We chose the second option in all our optimization runs but left the minimization of control effort term in the index of performance for future studies.

The optimization of the index of performance in (7) helps us to find safety stock levels and smoothing alphas for the forecast that will eliminate the unfilled orders at the retailer only. With the result we find, finished stocks of the retailer lowered in two scenarios much below the 1.5 weeks level. It is also observed that the smoothing factor alpha recommendation under these optimizations is closer 

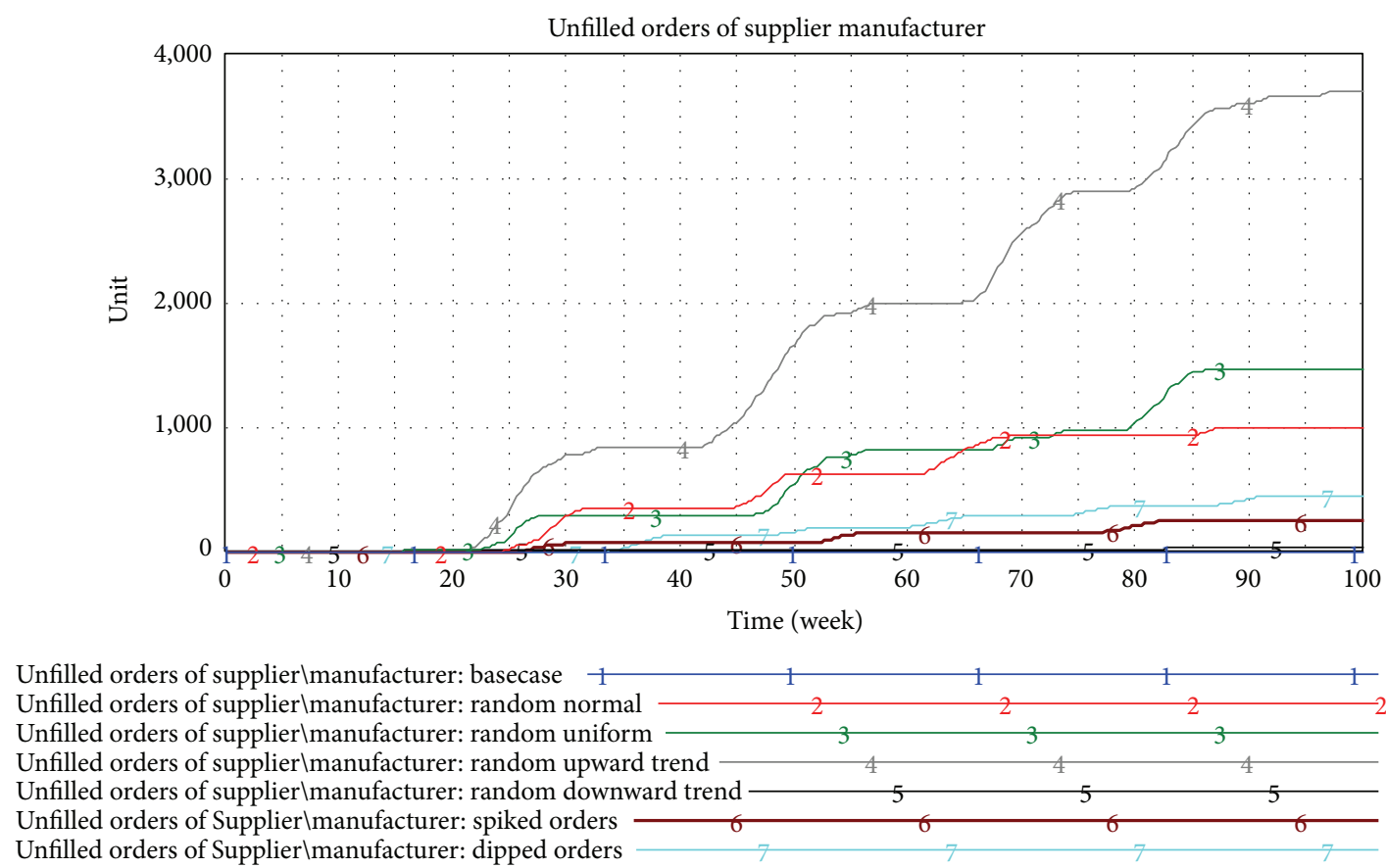

FIGURE 5: Unfilled orders at supplier/manufacturer despite information visibility and flexible work week policies.

TABLE 2: Customer order scenarios simulated.

\begin{tabular}{ll}
\hline Scenarios & Description \\
\hline Base case & $\begin{array}{l}\text { No changes in customer orders of 10,000 units/week, information } \\
\text { visibility turned off, and flexible work week is turned off } \\
\text { Starting week 16, customer orders vary between min of } 800 \text { and max } \\
\text { of } 1200 \text { with mean of } 1000 \text { and std. deviation of } 30\end{array}$ \\
Starting week 16, customer orders vary in a random uniform pattern \\
Random uniform & $\begin{array}{l}\text { Setween a low of } 800 \text { and high of } 1200 \\
\text { units/week and vary in a random uniform pattern of } \pm 200 \text { units on }\end{array}$ \\
Random upward trend & $\begin{array}{l}\text { either side of trend line } \\
\text { Starting week 16, customer orders show a downward trend of 5 }\end{array}$ \\
units/week and vary in a random uniform pattern of \pm 200 units on \\
either side of trend line \\
Random downward trend
\end{tabular}

In all scenarios, FWW: flexible work week switch is turned on. IV: information visibility switch is also turned on.

to 0 in five scenarios out of 6 for the retailer. The primary reason behind such recommendation is that, the increases in safety stocks are absorbing the fluctuations in the customer orders and as such there is no need to chase the demand in replenishments.

Another interesting observation would be the fact that supplier ends up with unfilled orders under random upward scenario. The main reason for this could be that the parameters have reached their range limits (1.5 weeks of safety stocks and smoothing factor alpha at 1.00) for the supplier. This need not be a very major concern because, after all, the focus in a supply chain should be to ensure filling all orders for the end user. But nevertheless, a further attempt at eliminating these unfilled orders at the supplier provides some counter intuitive benefits, elsewhere in the supply chain as will be seen in Optimization 2 scenario below.

Vensim Optimization. Figures 6 and 7 depict the process of settings to allow for selecting the payoff variable and defining the range of parametric values to search using the built-in optimization process. As discussed above, we used unfilled orders at the retailer as our objective and since the intent is 
to minimize it, we apply a weight of -1 (negative one) to it. Further, we specify the range of values to search not only for the "safety stock levels" but also for "smoothing factor alpha."

Optimization 2. To develop further insights, we refine our objective of minimizing "unfilled orders at the retailer" to a combined objective of minimizing unfilled orders at the retailer as well as the supplier with equal weight of $50 \%$ each for retailer and supplier (Optimization 2).

Our index of performance at this stage becomes:

$$
\begin{aligned}
\operatorname{Min} I= & \int_{t_{0}}^{t_{f}} C_{1} \cdot(\mathrm{UOR}) d t+\int_{t_{0}}^{t_{f}} C_{2} \cdot(\mathrm{UOS}) d t \\
& +\int_{t_{0}}^{t_{f}} C_{3} \cdot\|u-1\|_{w}^{2} d t .
\end{aligned}
$$

The first term seeks to minimize the unfilled orders at the retailer. The second term seeks to minimize the unfilled orders at the supplier. UOS denotes the "unfilled orders at the supplier." The third term minimizes the control effort required to accomplish the first two.

Consider the following:

$$
\begin{aligned}
& C_{1}=0.50 \text { (to reflect a } 50 \% \text { weight), } \\
& C_{2}=0.50 \text { (to reflect a } 50 \% \text { weight), } \\
& C_{3}=0 \text { as discussed earlier. }
\end{aligned}
$$

Not only do the unfilled orders remain zero at both retailer and supplier, but also there is a marked reduction in the inventory levels of retailer as a result of this objective, rather a counter intuitive result given that the objective is expanded to eliminate unfilled orders at both the retailer and the supplier. But a deeper analysis reveals that, if the supplier's unfilled orders are minimized, then retailers' requirements to maintain higher levels of stocks to absorb the order fluctuations fall down. After all, the retailer is able to depend on his supplier for all orders within the promised schedule; as such, retailer is able to reduce his safety stock levels to the extent of removal of uncertainty in this aspect.

Comparing results of Optimizations 1 and 2, we observe that inventory levels for the retailer drop down from being in the range of 1.25 weeks to 1.50 weeks to a range between 1.00 week to 1.31 weeks. In other words, the retailer stands to benefit in terms of reduced finished stock levels of nearly a quarter of a week (a drop of an average of 250 units in this case). However, we notice that the supplier's stocking levels do not show any significant reduction.

Optimization 3. A question of interest in this study is whether it's possible to reduce safety stocks without compromising

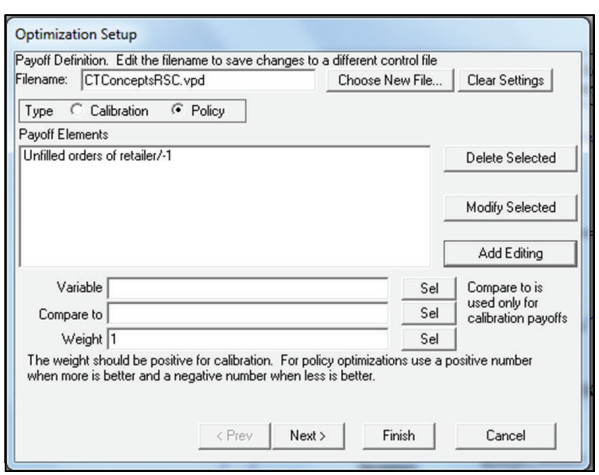

FIGURE 6: Selecting the payoff elements for optimization-objective is to minimize unfilled orders at the retailer.

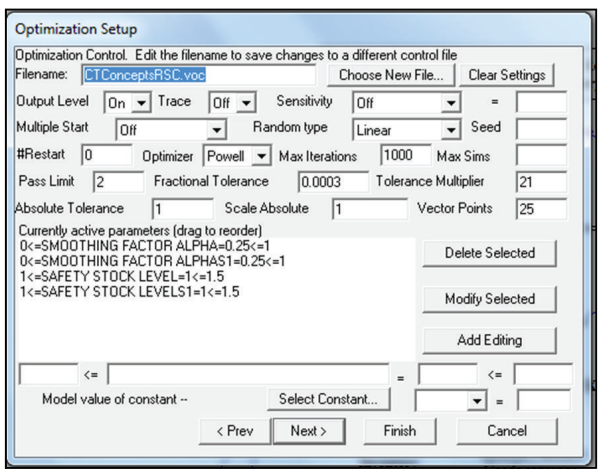

FIGURE 7: Selecting the search range for the parameters for optimization scenario.

on reduction of unfilled orders. To address that question, we redefine the index of performance as follows:

$$
\begin{aligned}
\operatorname{Min} I= & \int_{t_{0}}^{t_{f}} C_{1} \cdot(\mathrm{UOR}) d t+\int_{t_{0}}^{t_{f}} C_{2} \cdot(\mathrm{UOS}) d t \\
& +\int_{t_{0}}^{t_{f}} C_{3} \cdot(\mathrm{FGIR}) d t+\int_{t_{0}}^{t_{f}} C_{4} \cdot(\mathrm{FGIS}) d t \\
& +\int_{t_{0}}^{t_{f}} C_{5}\|u-1\|_{w}^{2} d t .
\end{aligned}
$$

FGIR denotes Finished Goods Inventory for Retailer and FGIS denotes Finished Goods Inventory for supplier.

This objective presupposes that we now view the system as

$$
I^{*}\left(u^{*}\right)=\lim _{u \in M} \int_{t_{0}}^{t_{f}} \phi(\mathrm{UOR}, \mathrm{UOS}, \mathrm{FGIR}, \mathrm{FGIS}, u, t) d t
$$
(6).

Subject to, the appropriate stipulations similar to those in

Since the inventory carrying costs depend upon the Finished Goods Stock and unfilled orders are measured in units of stocks, we use equal weights (0.25) for the coefficients $\left(C_{1}\right.$ thru $\left.C_{4}\right)$ of the four terms of the index of performance in Optimization 3 scenario.

Considerable improvement is found in Finished Goods stocking and surprisingly this optimization of composite 

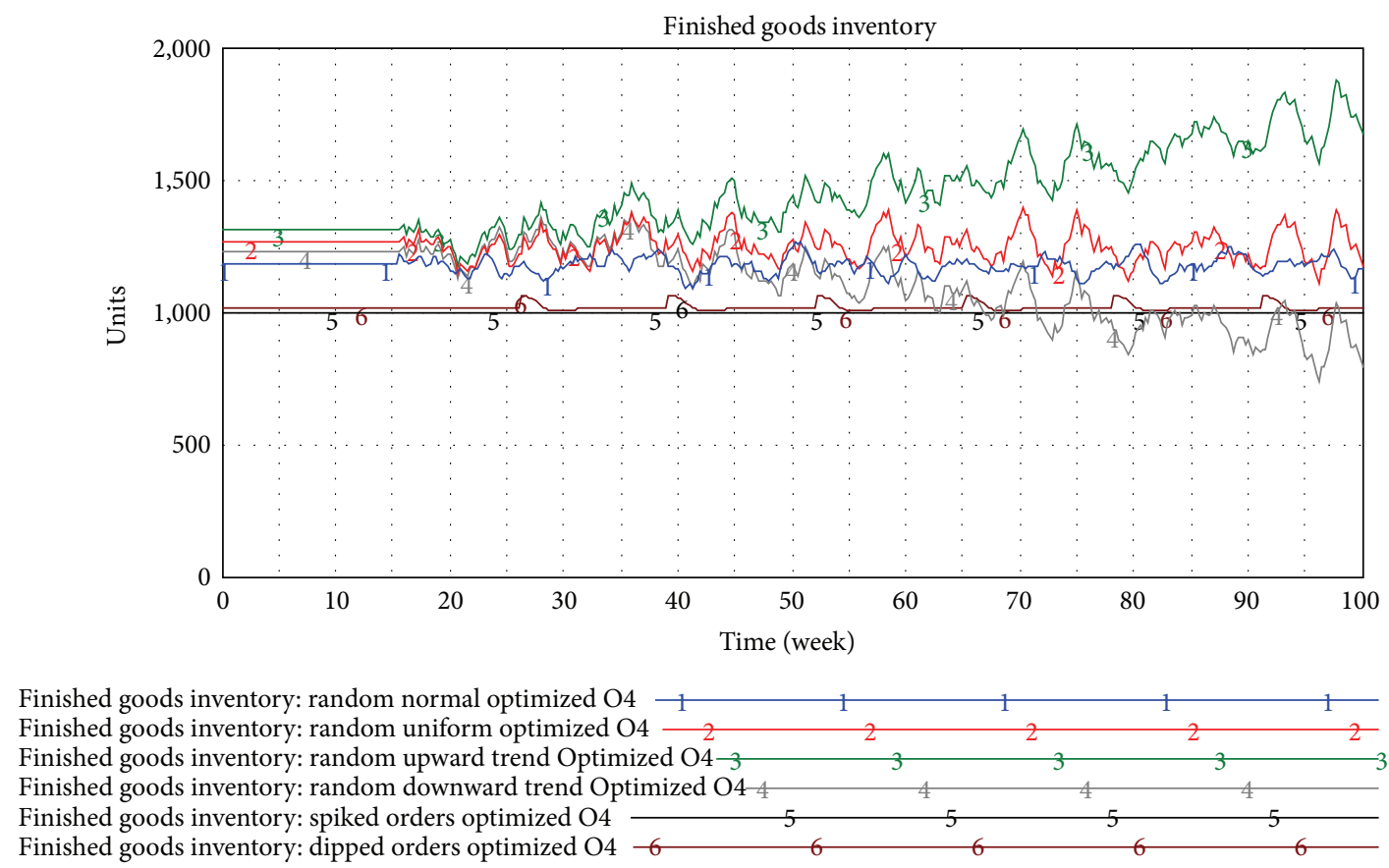

FIGURE 8: Improved Finished Goods levels for retailer with parametric optimization under composite objective including minimization of inventory costs.

objective function with equal weights for the terms appears to allow a very low number of unfilled orders (refer to Table 4), despite the restraint placed in terms of focus on elimination of unfilled orders. Apparently, the decision of equal weights to the four terms results in diversion of focus given exclusively to unfilled orders, now expanded to minimizing Finished Goods stocking as well. So if unfilled orders are to be eliminated "at any cost", the best option would be to limit the objective to unfilled orders only as was the case in the earlier version of the objective function, coupled with a broadened range of values for the input parameters.

Optimization 4. Let's now compare the impact of Finished Goods stocking to that of unfilled orders. Given that unfilled orders are reported in units of products, to facilitate an easier comparison, the inventory carrying costs can be expressed in terms of units, too. Typical inventory carrying costs run from $25 \%$ to $50 \%$ of inventory annually $[28,29]$. For the sake of simplicity, we can assume the annual carrying costs to be $26 \%$. Since our simulation time unit is a week, we divide 0.26 by 52 to arrive at the weekly inventory carrying cost (in units). So for example, if a week's Finished Goods stock is 10,000 units, then the carrying cost (in units) for that week is $10,000 \times$ $(0.26 / 52)=50$ units. So there is at least an order of magnitude difference in the impact of these two components, namely, unfilled orders and carrying costs. Accordingly, we must give greater importance to eliminating unfilled orders. We can use differential weights to these terms in the objective function; for example, we can use $0.46,0.04,0.46$, and 0.04 weights for the coefficients $\left(C_{1}\right.$ thru $\left.C_{4}\right)$ of the four terms of the index of performance which we choose to do in Optimization 4 scenario below.

Considerable improvement is found in Finished Goods stocking (Figure 8) and surprisingly, Optimization 4 scenario with differential weights too continues to allow a very low number of unfilled orders (Figure 9), despite a great restraint placed in terms of greater focus on elimination of unfilled orders versus Finished Goods carrying costs. However, this is noticed only in one scenario of the five simulated. Therefore, the policy of differential weights for the components of objective function does yield the desired result, albeit, not totally but substantially.

Nevertheless, if unfilled orders are to be eliminated "at any cost", the best option would be to operate at stocking levels closer to 1.5 weeks as seen in Table 3.

Results from the various optimization runs and simulations are listed in Tables 4 and 5. As may be noted from the parametric settings obtained under optimization runs, one's finding was reduced Finished Goods Inventory levels for the retailer under the composite objective of minimizing unfilled orders at both the retailer and supplier. Another most important insight is the picking by the optimization system of smoothing alpha $=1$ for the supplier. This selection denotes that the supplier need not forecast but simply follow the retailer's forecast as input. This second important finding supports the concept that in supply chains exogenous input is the customer order. As such, retailer who deals with customer only need forecast orders. The upstream suppliers would simply follow downstream partners forecasts as input. A rather similar phenomenon is described as "flow casting" rather than forecasting by Martin et al. [30], from a different 
TABLE 3: Base Case and alternate scenarios without and with increase in Safety stocks.

\begin{tabular}{|c|c|c|c|c|c|c|}
\hline \multirow{2}{*}{$\begin{array}{l}\text { Supplier-retailer model results } \\
\text { Parameters }\end{array}$} & \multicolumn{3}{|c|}{ Base case scenario results } & \multicolumn{3}{|c|}{ Finished Goods increased scenario results } \\
\hline & Safety stocks & $\begin{array}{c}\text { Smoothing } \\
\text { factor alpha/S1 }\end{array}$ & Unfilled orders & Safety stocks & $\begin{array}{c}\text { Smoothing } \\
\text { factor alpha/S1 }\end{array}$ & Unfilled orders \\
\hline Base case-supplier & 1.00 & 0.25 & 0 & n.a. & n.a. & n.a. \\
\hline Base case-retailer & 1.00 & 0.25 & 0 & n.a. & n.a. & n.a. \\
\hline Random normal-supplier & 1.00 & 0.25 & 998 & 1.50 & 0.25 & 0 \\
\hline Random normal-retailer & 1.00 & 0.25 & 1761 & 1.50 & 0.25 & 0 \\
\hline Random uniform-supplier & 1.00 & 0.25 & 1455 & 1.50 & 0.25 & 0 \\
\hline Random uniform-retailer & 1.00 & 0.25 & 3413 & 1.50 & 0.25 & 0 \\
\hline Random upward-supplier & 1.00 & 0.25 & 3700 & 1.50 & 0.25 & 0 \\
\hline Random upward-retailer & 1.00 & 0.25 & 5565 & 1.50 & 0.25 & 0 \\
\hline Random downward-supplier & 1.00 & 0.25 & 38 & 1.50 & 0.25 & 0 \\
\hline Random downward-retailer & 1.00 & 0.25 & 1940 & 1.50 & 0.25 & 0 \\
\hline Spiked-supplier & 1.00 & 0.25 & 247 & 1.50 & 0.25 & 0 \\
\hline Spiked-retailer & 1.00 & 0.25 & 314 & 1.50 & 0.25 & 0 \\
\hline Dipped-supplier & 1.00 & 0.25 & 448 & 1.50 & 0.25 & 0 \\
\hline Dipped-retailer & 1.00 & 0.25 & 473 & 1.50 & 0.25 & 0 \\
\hline
\end{tabular}

TABLE 4: Parameter settings and results from optimization runs.

\begin{tabular}{|c|c|c|c|c|c|c|c|c|c|}
\hline \multirow{2}{*}{$\begin{array}{l}\text { Optimization results } \\
\text { Parameters }\end{array}$} & \multicolumn{3}{|c|}{$\begin{array}{l}\text { Optimization 1-minimize } \\
\text { unfilled orders of retailer } \\
\text { alone }\end{array}$} & \multicolumn{3}{|c|}{$\begin{array}{l}\text { Optimization 2-minimize } \\
\text { unfilled orders of both SC } \\
\text { partners }\end{array}$} & \multicolumn{3}{|c|}{$\begin{array}{l}\text { Optimization 3-minimize } \\
\text { unfilled orders and Finished } \\
\text { Goods stocking of both SC } \\
\text { partners-(equal weight for all } \\
\text { components) }\end{array}$} \\
\hline & $\begin{array}{l}\text { Safety } \\
\text { stocks }\end{array}$ & $\begin{array}{l}\text { Smoothing } \\
\text { factor } \\
\text { alpha/S1 }\end{array}$ & $\begin{array}{l}\text { Unfilled } \\
\text { orders }\end{array}$ & $\begin{array}{l}\text { Safety } \\
\text { stocks }\end{array}$ & $\begin{array}{l}\text { Smoothing } \\
\text { factor } \\
\text { alpha/S1 }\end{array}$ & $\begin{array}{l}\text { Unfilled } \\
\text { orders }\end{array}$ & $\begin{array}{l}\text { Safety } \\
\text { stocks }\end{array}$ & $\begin{array}{l}\text { Smoothing } \\
\text { factor } \\
\text { alpha/S1 }\end{array}$ & $\begin{array}{c}\text { Unfilled } \\
\text { orders }\end{array}$ \\
\hline $\begin{array}{l}\text { Random normal } \\
\text { optimized-supplier }\end{array}$ & 1.50 & 0.00 & 0 & 1.50 & 0.02 & 0 & 1.21 & 0.00 & 0 \\
\hline $\begin{array}{l}\text { Random normal } \\
\text { optimized-retailer }\end{array}$ & 1.50 & 0.06 & 0 & 1.20 & 0.15 & 0 & 1.18 & 0.00 & 0 \\
\hline $\begin{array}{l}\text { Random uniform } \\
\text { optimized-supplier }\end{array}$ & 1.50 & 1.00 & 0 & 1.38 & 1.00 & 0 & 1.35 & 0.00 & 0 \\
\hline $\begin{array}{l}\text { Random uniform } \\
\text { optimized-retailer }\end{array}$ & 1.50 & 0.12 & 0 & 1.28 & 0.12 & 0 & 1.26 & 0.00 & 18 \\
\hline $\begin{array}{l}\text { Random upward } \\
\text { optimized-supplier }\end{array}$ & 1.50 & 1.00 & 234 & 1.50 & 1.00 & 0 & 1.50 & 0.60 & 0 \\
\hline $\begin{array}{l}\text { Random upward } \\
\text { optimized-retailer }\end{array}$ & 1.50 & 1.00 & 0 & 1.31 & 0.11 & 0 & 1.31 & 0.09 & 1 \\
\hline $\begin{array}{l}\text { Random downward } \\
\text { optimized-supplier }\end{array}$ & 1.50 & 0.25 & 0 & 1.50 & 0.05 & 0 & 1.22 & 0.42 & 0 \\
\hline $\begin{array}{l}\text { Random downward } \\
\text { optimized-retailer }\end{array}$ & 1.50 & 0.00 & 0 & 1.29 & 0.00 & 0 & 1.22 & 0.09 & 2 \\
\hline Spiked optimized-supplier & 1.50 & 0.04 & 0 & 1.50 & 0.25 & 0 & 1.00 & 0.25 & 0 \\
\hline Spiked optimized-retailer & 1.25 & 0.06 & 0 & 1.00 & 0.00 & 300 & 1.00 & 0.00 & 300 \\
\hline Dipped optimized-supplier & 1.50 & 0.00 & 0 & 1.50 & 0.00 & 0 & 1.02 & 0.00 & 0 \\
\hline Dipped optimized-retailer & 1.25 & 0.00 & 0 & 1.25 & 0.00 & 0 & 1.01 & 0.00 & 0 \\
\hline
\end{tabular}

In all optimization scenarios, FWW: flexible work week switch is turned on. IV: information visbility switch is also turned on. 

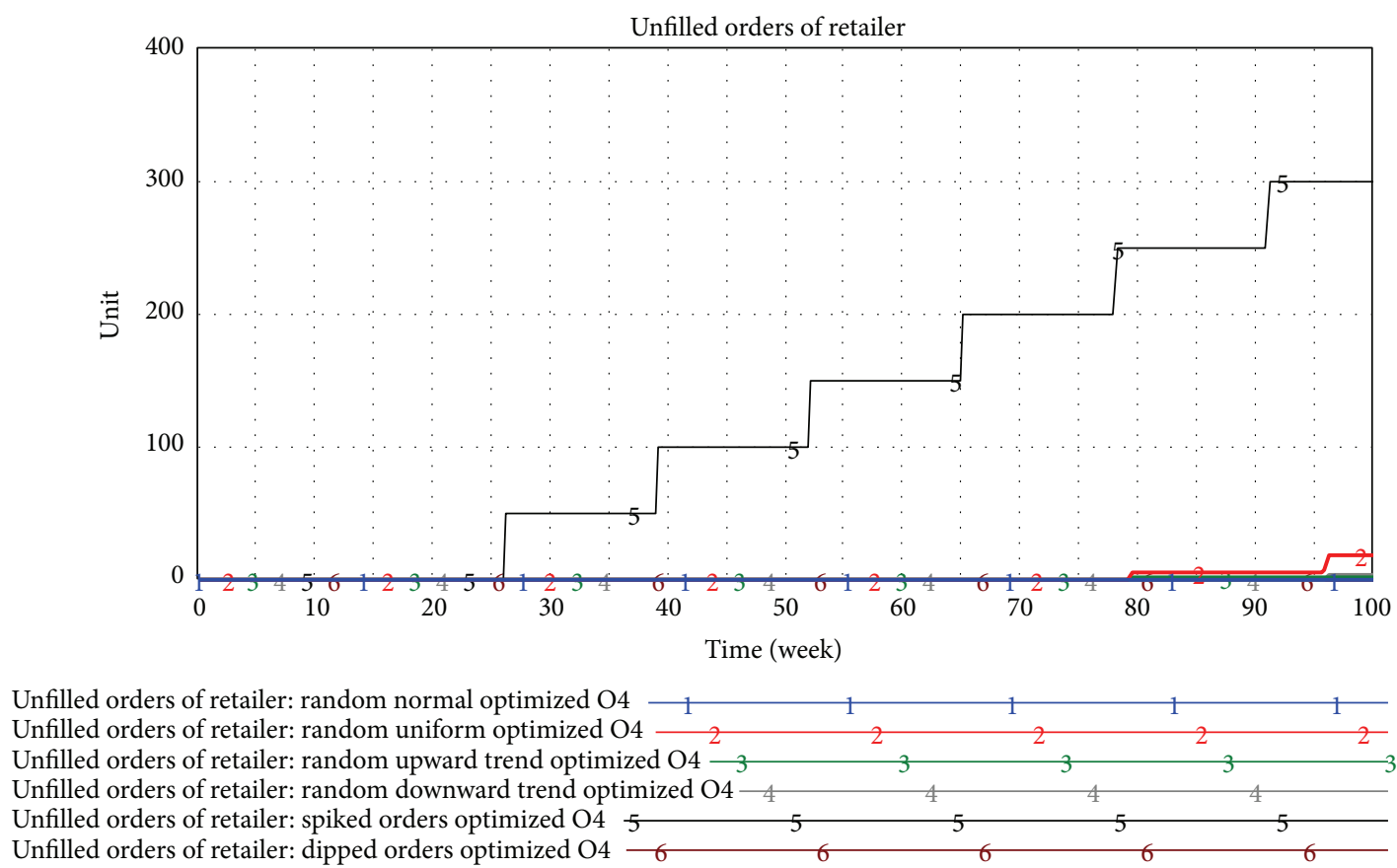

Figure 9: Unfilled orders at retailer despite higher weight for unfilled order component in the objective under Optimization 4.

approach to the issue. Based on the results from this study, it now appears to be valid from a system dynamics perspective as well.

All parameters of Table 3 are handpicked. While all parameters reported in Tables 4 and 5 under optimization scenarios were picked by the Vensim System while optimizing the respective objective function. However, it must be noted that the system-picked parametric values are not a unique set of parameters but are one of the several sets of parameters yielding highest payoff values for the objective function. Also, it must be remembered, that we have defined the starting point of search based on the initial starting value of parameters with the assumption that it must be easier to make a transition from staring value to the proposed set found, given the manner in which Powel Hill Climbing algorithm searches for optimal settings. For obvious reasons, it's possible to hold certain parameters to be constant and search for the acceptable/desirable value of other parameters to accomplish the same or substantially same objective function as well. For example, management may decide that as a policy they want to stock Finished Goods at 1.25 week level. Then one could stipulate that aspect in the optimization settings and look for a desirable value for smoothing factor alpha and possibly, focus on reducing or increasing the "production cycle time" or "order filling time" parameters. In other words, several permutations and combinations are possible in terms of the components of the objective functions, their corresponding weights, and parameter starting values and desirable range of allowable values for those parameters.

As was seen, if elimination of unfilled orders is the sole objective, which might very well be in a retail supply chain, increases in inventory to meet the surges in fluctuations in the customer order patterns will suffice as a suitable strategy. This is not a very surprising result given that one of the major functions of an inventory is to serve as a "safety stock" against unforeseen fluctuations. However, businesses are focused on achieving the desired objectives at the least possible cost as long as such policy does not impair the sustainable operations of the firm in general and the strategy is not infeasible or impractical. For obvious reasons, the efforts in implementing the new policy should cost less than the benefit to be derived from such implementation.

What we find in this model is that, in a seemingly straight forward supply chain, the fluctuations in orders can cause multiple feedback effects on the variables involved. Use of system dynamics modeling allows the user to capture the resultant behavior over time of the variables involved so that suitable corrective action may be planned and tested while focusing on the desired objective or combinations of objectives.

\section{Conclusions, Limitations, and Future Studies}

4.1. Conclusions. Given that production cycle time cannot be crashed beyond a point due to inherent transformation delays, both retailer and supplier are best served when these partners in a supply chain share information in real time to remove all the avoidable information delays that would compound the cycle time delay and cause a severe destabilizing effect on supply chain functioning.

Further, the study also suggests that both parties should understand the dynamics involved in material flow and desist from taking aggressive corrective action before gaining such 
TABle 5: Parameter settings and results from optimization run with differential weights for the components of objective function.

Optimization results Optimization 4-minimize unfilled orders and Finished Goods stocking of both SC partners-with $0.46,0.04,0.46$, and 0.04 weights for $\left(C_{1}-C_{4}\right)$

\begin{tabular}{lccc}
\hline Parameters & Safety stocks & Smoothing factor alpha/S1 & Unfilled orders \\
\hline Random normal optimized O4-supplier & 1.21 & 0.00 & 0 \\
Random normal optimized O4-retailer & 1.18 & 0.00 & 0 \\
Random uniform optimized O4-supplier & 1.33 & 0.99 & 0 \\
Random uniform optimized O4-retailer & 1.27 & 0.06 & 0 \\
Random upward optimized O4-supplier & 1.50 & 1.00 & 0 \\
Random upward optimized O4-retailer & 1.31 & 0.11 & 0 \\
Random downward optimized & 1.17 & 0.05 & 0 \\
O4-supplier & 1.22 & 0.00 & 0 \\
Random downward optimized & 1.00 & 0.25 & 0 \\
O4-retailer & 1.00 & 0.00 & 300 \\
Spiked optimized O4-supplier & 1.02 & 0.00 & 0 \\
Spiked optimized O4-retailer & 1.01 & 0.00 & 0 \\
Dipped optimized O4-supplier & & & \\
Dipped optimized O4-retailer & & & 0 \\
\end{tabular}

understanding, or such actions may result in counterintuitive and often counterproductive unintended effects on the smooth operation of the supply chain.

Interestingly, the results of the study indicate that increases in safety stock may be a cost-effective strategy to achieve the objective of minimizing unfilled orders in a volatile customer-orders scenario. In other words, the study makes a pretty strong case, with indisputable evidence, against a euphoric implementation of just in time replenishment systems.

Our study suggests that while the supplier accepts the retailer's orders as input, the supplier also needs to make suitable adjustments in his production setup to absorb the resulting shocks, say by allowing overtime work (or otherwise) by his workers and so on.

The study also demonstrates the usefulness of defining a suitable performance functional for optimization purposes to accomplish desired results without losing sight of the overriding conditions. Because of the high priority placed on zero unfilled orders, a suitable performance functional was shown to be one in which unfilled orders at both the retailer and supplier are minimized without consideration of inventory carrying costs (a much lower priority objective). Whereas, when the performance functional included minimizing the unfilled order as well as lowering the inventory carrying costs, the optimal parametric setting recommendation was different.

The study also demonstrated how multiple objectives can be combined in a single performance functional by carefully assigning suitable weights to the objectives based on their priority and the existence of possible trade off opportunities.

Finally, the study found that minimization of unfilled orders at both the supplier as well as the retailer, and helped to lower the need for Finished Goods Inventory at the retailer for most scenarios the high-variability, uniformlydistributed customer-orders scenario is excepted. This seems quite rational. If the supplier can always be counted on to provide goods when ordered, then lesser Finished Goods Inventories at the retailer are required as opposed to scenarios where the supplier does not guarantee providing goods when needed. Financial gains from choosing the right policies vary by the industry and associated inventory costs.

4.2. Limitations/Assumptions of the Model. Although the model captures the typical supply chain behavior observed in the real world, there is no denying that the model is simplified compared to the complex real world. The model is parsimonious in that it captures the dynamic essence of the generic retailer/supplier supply chain with minimal structure. The following explicit assumptions helped simplify the model: (a) uniform shipping cost per unit, (b) uniform ordering costs, (c) decimal values are allowed in the workforce numbers, (d) supplier is assumed to be servicing a retailer, and (e) sufficient surplus capacities at supplier are assumed to be available.

4.3. Future Studies. Further studies will focus on obtaining more useful insights into other possible scenarios involving different patterns of customer orders, like cyclic or seasonal patterns, coupled with trends. Additionally, future studies would focus on minimizing the control effort required to minimize the other objectives.

\section{References}

[1] J. W. Forrester, Industrial Dynamics, Productivity, Pegasus Communications, Waltham, Mass, USA, 1961. 
[2] J. D. Sterman, Business Dynamics: Systems Thinking and Modeling for a Complex World, McGraw-Hill, Boston, Mass, USA, 2000 .

[3] B. Janamanchi and J. R. Burns, "Reducing bullwhip oscillation in a supply chain: a system dynamics model-based study," International Journal of Information Systems and Change Management, vol. 2, no. 4, pp. 350-371, 2007.

[4] B. Janamanchi and J. R. Burns, "Simulation studies of the effects of safety stock and related policies upon Bullwhip oscillation in supply chains," International Journal of Information Systems and Change Management, vol. 3, no. 2, pp. 171-187, 2008.

[5] H. L. Lee, V. Padmanabhan, and S. Whang, "Information distortion in a supply chain: the bullwhip effect," Management Science, vol. 43, no. 4, pp. 546-558, 1997.

[6] H. L. Lee, V. Padmanabhan, and S. Whang, "The bullwhip effect in supply chains," Sloan Management Review, vol. 38, no. 3, pp. 93-102, 1997.

[7] J. M. Swaminathan, S. F. Smith, and N. M. Sadeh, "Modeling supply chain dynamics: a multiagent approach," Decision Sciences, vol. 29, no. 3, pp. 607-631, 1998.

[8] F. Chen, Z. Drezner, J. K. Ryan, and D. Simchi-Levi, "Quantifying the bullwhip effect in a simple supply chain: the impact of forecasting, lead times, and information," Management Science, vol. 46, no. 3, pp. 436-443, 2000.

[9] G. Q. Huang, J. S. K. Lau, and K. L. Mak, “The impacts of sharing production information on supply chain dynamics: a review of the literature," International Journal of Production Research, vol. 41, no. 7, pp. 1483-1517, 2003.

[10] E. Fleisch and C. Tellkamp, "Inventory inaccuracy and supply chain performance: a simulation study of a retail supply chain," International Journal of Production Economics, vol. 95, no. 3, pp. 373-385, 2005.

[11] N. Agrawal, S. A. Smith, and A. A. Tsay, "Multi-vendor sourcing in a retail supply chain," Production and Operations Management, vol. 11, no. 2, pp. 157-181, 2002.

[12] D. Sparling, "Simulations and supply chains: strategies for teaching supply chain management," Supply Chain Management, vol. 7, no. 5, pp. 334-342, 2002.

[13] J. L. Kent and J. T. Mentzer, "The effect of investment in interorganizational information technology in a retail supply chain," Journal of Business Logistics, vol. 24, no. 2, pp. 155-175, 2003.

[14] M. Holweg, S. Disney, J. Holmström, and J. Småros, "Supply chain collaboration: making sense of the strategy continuum," European Management Journal, vol. 23, no. 2, pp. 170-181, 2005.

[15] M. Barratt and A. Oke, "Antecedents of supply chain visibility in retail supply chains: a resource-based theory perspective," Journal of Operations Management, vol. 25, no. 6, pp. 1217-1233, 2007.

[16] M. Y. Jaber, M. Bonney, and A. L. Guiffrida, "Coordinating a three-level supply chain with learning-based continuous improvement," International Journal of Production Economics, vol. 127, no. 1, pp. 27-38, 2010.

[17] H. Ding, B. Guo, and Z. Liu, "Information sharing and profit allotment based on supply chain cooperation," International Journal of Production Economics, vol. 133, no. 1, pp. 70-79, 2011.

[18] J. R. Burns and D. W. Malone, "Optimizationtechniques applied to the Forrester model of the world," IEEE Transactions on Systems, Man and Cybernetics, vol. 4, no. 2, pp. 164-171, 1974.

[19] J. R. Burns, Applications of control theory to system dynamics models of social systems [Ph.D. dissertation], Purdue University, Lafayette, Ind, USA, 1973.
[20] B. Janamanchi and J. R. Burns, "Offshoring knowledge worker jobs: boom or burst for the US economy," in Proceedings of the 23rd International Conference of System Dynamics Society, Boston, Mass, USA, 2005, http://www.systemdynamics.org/ conferences/2005/proceed/papers/BURNS187.pdf.

[21] Ventana Systems Inc., 2013, http://www.vensim.com/.

[22] J. W. Forrester, "Industrial dynamics: a major breakthrough for decision makers," Harvard Business Review, vol. 36, no. 4, pp. 37-66, 1958.

[23] H. Akkermans and N. Dellaert, "The rediscovery of industrial dynamics: the contribution of system dynamics to supply chain management in a dynamic and fragmented world," System Dynamics Review, vol. 21, no. 3, pp. 173-186, 2005.

[24] R. Croson and K. Donohue, "Upstream versus downstream information and its impact on the bullwhip effect," System Dynamics Review, vol. 21, no. 3, pp. 249-260, 2005.

[25] R. Croson and K. Donohue, "Impact of POS data sharing on supply chain management: an experimental study," Production and Operations Management, vol. 12, no. 1, pp. 1-11, 2003.

[26] J. D. C. Little, "A proof for the queuing formula: $L=\lambda W$," Operations Research, vol. 9, no. 3, pp. 383-387, 1961.

[27] J. Burns and B. Janamanchi, "Optimal control and optimization of system dynamics models: some experiences and recommendations," in Proceedings of the SWDSI Conference, San Diego, Calif, USA, March 2007.

[28] P. R. Murphy and D. F. Wood, Contemporary Logistics, Prentice Hall, Upper Saddle River, NJ, USA, 2004.

[29] R. S. Russell and B. W. Taylor, Operations Management: Creating Value Along the Supply Chain, John Wiley \& Sons, Hoboken, NJ, USA, 6th edition, 2009.

[30] A. Martin, M. Doherty, and J. Harrop, Flowcasting the Retail Supply Chain, 2006, http://www.flowcastingbook.com/index .htm. 

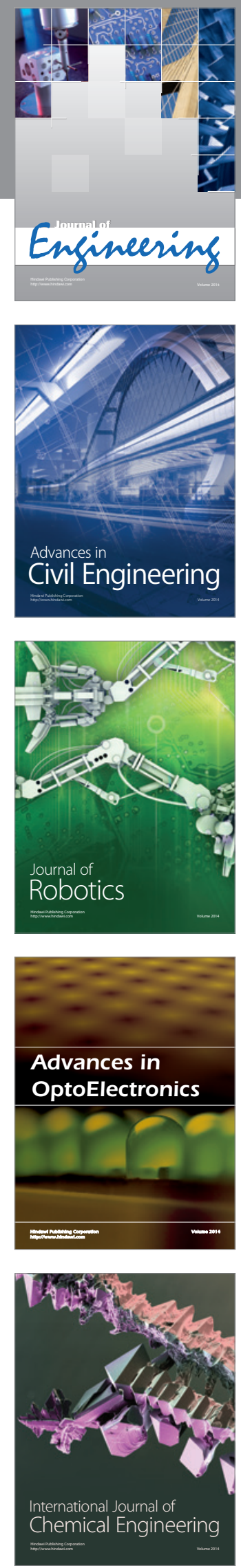

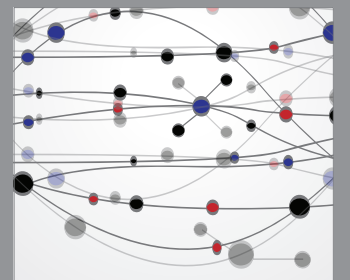

The Scientific World Journal
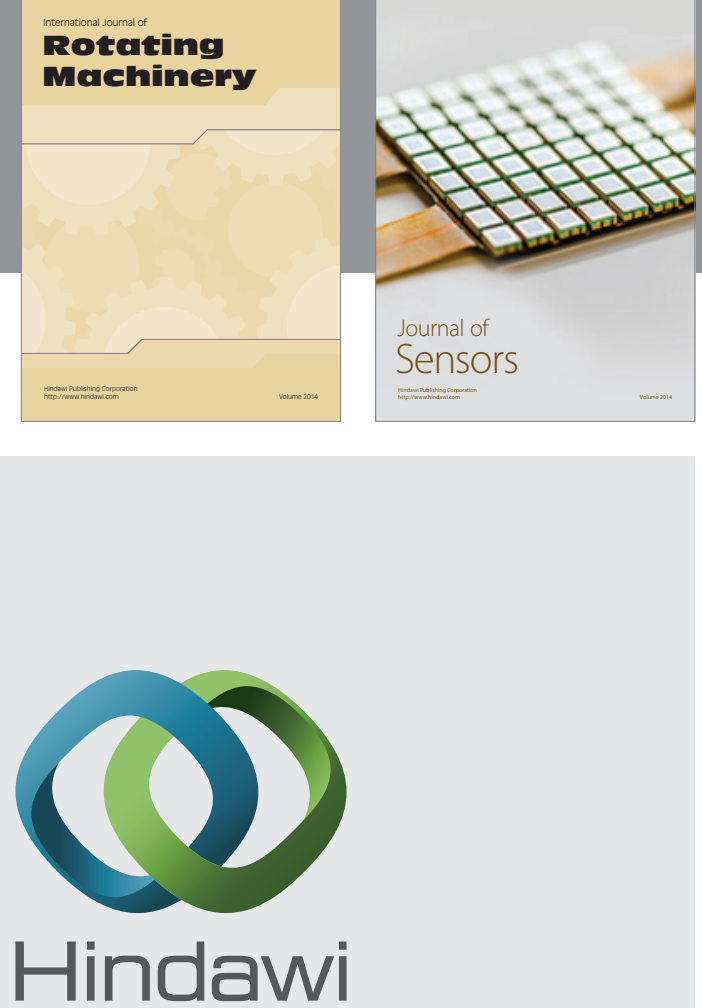

Submit your manuscripts at http://www.hindawi.com
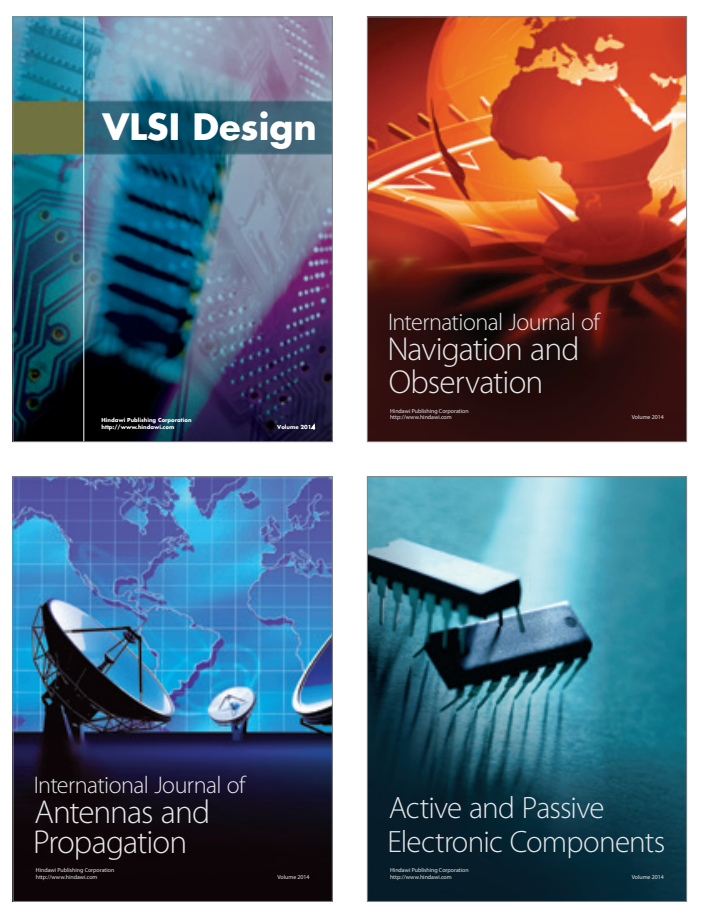
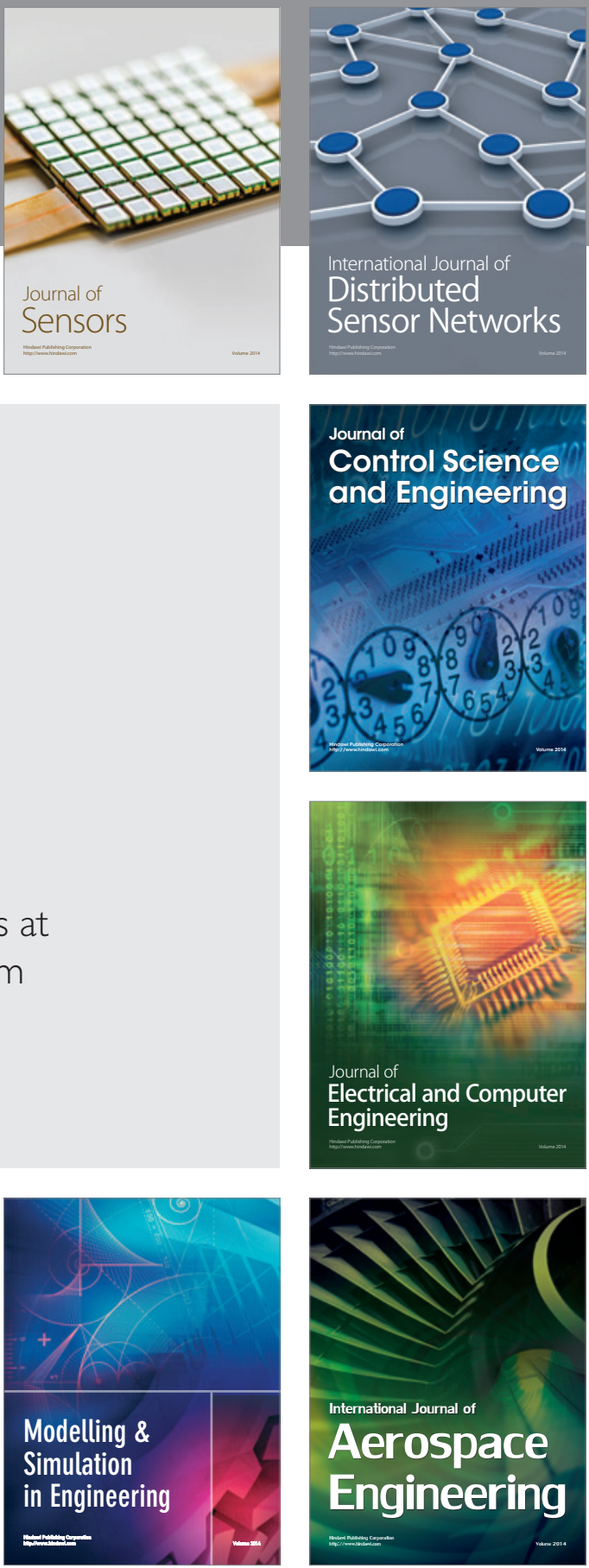

Journal of

Control Science

and Engineering
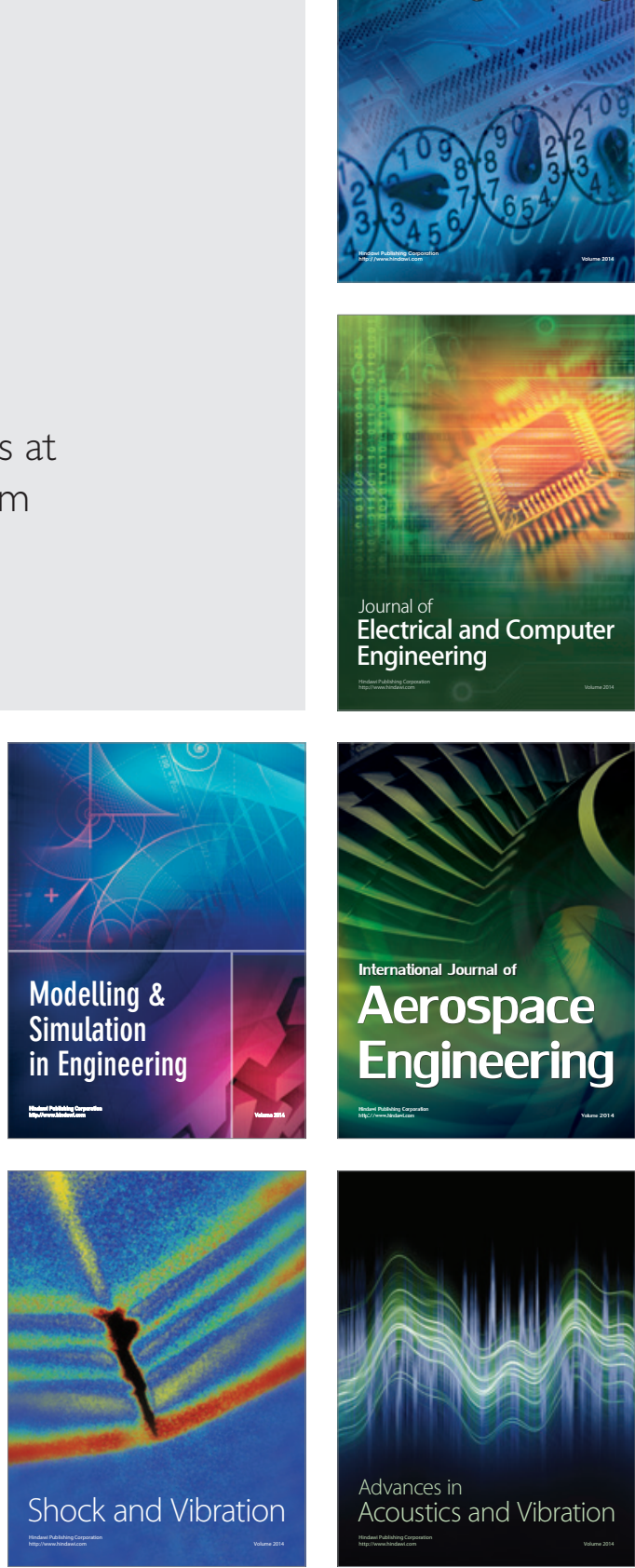